\title{
Study on the Value of Time-honored Brands in Anhui
}

\author{
Bingjie Wang ${ }^{a}$, Jian Gao ${ }^{b}$, Yuting Wu ${ }^{c}$ \\ Hefei University of Technology

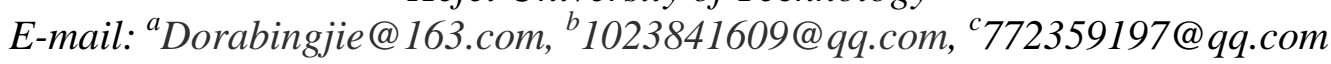

Keywords: Anhui Province; time-honored brands; brand value; THBV model

\begin{abstract}
At present, there are some headwinds in the development of time-honored brands in Anhui Province in China, and the measurements of brand value lack a unified standard. Therefore, the brand value evaluations and promotion strategies of time-honored brands should be put forward urgently. This paper analyzes present situations of liquor and alcoholic beverage in Anhui Province, then values the two time-honored brands by using the current most THBV model valuation, comparing the differences between the two time-honored brands in Anhui Province, and puts forward strategies of brand value promotion, striving for the development of time-honored brands in Anhui Province.
\end{abstract}

\section{Introduction}

The Chinese time-honored brand is a special appellation. The ministry of commerce gives a clear definition of it in the Chinese time-honored brand recognition standard. "A Chinese time-honored brand shows the value of the cultural creativity of the Chinese nation. And it has a distinctive Chinese traditional cultural background with a unique technology of patrimony or operating characteristics. Also as an enterprise and (or) a product brand, it has obtained the widespread recognition and good business reputation. There are 25 time-honored brands in Anhui province at present. The top three of them are dead HUILIU, Kouzijiao liquor and Red Star. Overall, China's time-honored brands are not doing well. Of more than 2,000 time-honored enterprises, only 10\% of them have good returns and a certain scale of production. About $70 \%$ of them tend to decline, and their operations barely maintain their original status. 20\% of them suffer long-term losses. They overly dependent on their past achievements, and ignore the development, just stick to traditional features, also lack of innovation, and are not closely integrated with the Times. In addition, the customer base cannot be expanded, and the brand effect cannot be driven naturally for lacking of publicity and participation of fresh blood, which leads to the decline of operating benefits.

\section{Literature Review}

The existing literature researches on brand value evaluation system mainly include financial analysis, market analysis and consumer analysis. The research points out that at present the two major research areas of brand evaluation are brand competitiveness evaluation and brand value evaluation (Qian Minghui, 2017). Existing studies evaluate brand symbol value, performance value, image value and emotional value, and focus on the influence, viability and brand development power. (Chen Zhongwei et al, 2010). Wang Chengrong (2012) proposed THBV evaluation method, 
the only evaluation method domestic for unique cultural characteristics and market features of the proposed brand value, and it original introduced historical and cultural aspects such as social and cultural implications index.

Currently Wang Chengrong's (2012) THBV model theory has strong maneuverability. Many researchers are making historical and cultural aspects in-depth and extensive research. And they continue to expand the brand value evaluation content and improve its accuracy by using the existing evaluation methods. However, this model lacks the influence of the Internet utilization degree of Chinese time-honored brand on the brand value, which needs to be further improved and revised. Summarizing evaluation methods' advantages and disadvantages in order to highlight the time-honored brands' unique cultural history, this thesis value evaluation is based on THBV and its modification. Therefore, it is of great theoretical and practical significance to propose a targeted strategy to enhance the value of Chinese time-honored brands in order to facilitate the second revival of them.

\section{Internet THBV Brand Value Evaluation Model of Chinese Time-honored Brands}

The model includes four basic formulas. Formula 1: brand value $(\mathrm{BV})=$ brand advantage value $(\mathrm{BAV}) *$ brand multiplier $(\mathrm{BM})$; Formula 2: brand advantage value $(\mathrm{BAV})=$ real brand advantage value (RBAV) * potential market advantage multiplier (PBVM); Formula 3: real brand advantage value $(\mathrm{RBAV})=$ after-tax profit of the evaluated brand $(\mathrm{P})$-- average after-tax profit of the industry (AP)/ average profit rate of the industry (APR); Formula 4:potential market advantage multiplier = $\alpha+\beta 1$ demographic variables $+\beta 2$ brands social and cultural implications recognition $+\beta 3$ emotional and psychological recognition $+\beta 4$ brand recognition quality $+\varepsilon$.

This paper combines formulas of THBV time-honored value evaluation model with the methods of questionnaire survey and expert evaluation. The processes of the research are mainly based on the basic situation of Gujing liquor and Kouzi liquor in 2016. The evaluation process includes the validity analysis of model building and structure, data collection and brand value analysis based on the model data in the view of the producers, consumers and experts. Finally it concludes the value of liquor time-honored brand through the Kouzi liquor and Gujing liquor value analysis.

\section{Brand Value Evaluation of Anhui Time-honored Brand--based on THBV Model}

Gujing and Kouzijiao respectively represent the mature types and less mature ones with wide coverage and a certain reference value.

\subsection{Brand value assessment from the perspective of producers}

The evaluation of brand value from the perspective of producers involves two dimensions, that is the calculation of real brand advantage value (RBAV) and the calculation of Internet multiplier (IM).

Table 1 RBAV calculation index of time-honored brands

\begin{tabular}{ccccc}
\hline Year 2016 & 1 & $(2)$ & $(3)$ & (4) \\
\hline Kouzijiao & 7.83 & 28.30 & 0.277 & 56.18 \\
Gujing & 8.30 & 60.17 & 0.138 & 59.77 \\
The industry average & 0.47 & 3.56 & 0.131 & \\
\hline
\end{tabular}

(1) Net profit after tax (100 million yuan) (2) Sales revenue (hundred million yuan)

(3) Profit margin (4) Real brand advantage value (100 million yuan)

Calculate the real brand advantage value (RBAV). Through the analysis of the income statement 
of Kouzijiao Liquor Company and Gujing Liquor Company in 2016, you can get the net profit after-tax, sales revenue, profit margins about the two brands, and calculate the real brand advantage value (RBAV) by using the three indicators.

From the financial statements, net profit after-tax, sales revenue, profit margins of Kouzijiao and Gujing are all higher than industry average so their BVs are both high.

\subsection{Indicators analysis of THBV model based on the perspective of consumers}

This paper designs a questionnaire based on brand recognition, reputation and trust, and evaluates brand recognition, reputation and trust by means of consumer rating. While spreading the questionnaires, there are online and offline questionnaires. Online survey is conducted in Anhui province's shopping malls, hotels and other related places of alcohol consumption. People who have certain needs for the liquor products were selected as questionnaire audiences with more than 500 questionnaires distributed. In addition, the data obtained from the questionnaire survey were classified, and the values of each quantitative question in the questionnaire were weighted and averaged for the calculation of each index in the model.

\subsubsection{Calculate potential brand value multiplier (PBVM).}

Data is from the questionnaire, including brand awareness (3.69), brand reputation (3.53) and brand trust (3.75). The three dimensions data was respectively one-to-one correspondence to the social and cultural implications recognition, emotional and psychological awareness and brand quality awareness. As a result of that, we can get the value of the above indicators. Due to the sameness of the two brands of demographic variables, $\beta 1$ and $\alpha$ in the formula should take 0 . In order to ensure that the PBVM numerical value is between 1 and 2, the coefficient before the social and cultural implications recognition, emotional and psychological awareness, brand quality awareness which named $\beta 2, \beta 3, \beta 4$ were taken $1 / 6$ of each. So it can be concluded that the time-honored enterprises PBVM is as follows:

Table 2 PBVM indicators

\begin{tabular}{clllll}
\hline & 1 & $(2)$ & $(3)$ & (4) & PBVM \\
\hline Kouzijiao & 540 & 3.69 & 3.53 & 3.75 & 1.82 \\
Gujing & 540 & 3.78 & 3.61 & 3.75 & 1.85 \\
\hline
\end{tabular}

(1)Demographic statistics variables (2)Social and cultural implication awareness

(3)Social and cultural implication awareness (4)Recognition of brand quality

Recognition of brand quality of Kouzijiao and Gujing is roughly equal, but the social and cultural implications recognition, emotional and mental awareness indicators of Gujing is relatively higher than that of Kouzijiao, which shows its high recognition in the consumers. From the perspective of the PBVM, the social and cultural value of Gujing brand is higher than that of Kouzijiao.

\subsubsection{Calculate the brand advantage value (BAV).}

According to the real brand advantage value (RBAV) and above PBVM data, the value of brand advantage value (BAV) can be calculated as follows: 
Table 3 Indicators of brand advantage

\begin{tabular}{cclc}
\hline & RBAV & PBVM & BAV \\
\hline Kouzijiao & 56.18 & 1.82 & 102.25 \\
Gujing & 59.77 & 1.85 & 110.57 \\
\hline
\end{tabular}

BAV of Gujing is 8.14\% which is higher than that of Kouzi and it indicates that there is a large gap in the brand advantage value of the time-honored brand industries.

\subsection{THBV model analysis from an expert perspective}

\subsubsection{Calculation brand multiplier (BM).}

According to the expert evaluation, the brand multiplier of Kouzijiao and Gujing was calculated respectively. Brand multiplier factors include five parts, brand history, culture, management idea and strategy, traditional technology and art, architectural remains and relics. The corresponding weight ratio was established according to the liquor time honored brand and their own advantages and development environment,. In view of the balanced effect of the brand multiplier factors of the brands of Gujing and Kouzijiao, the brand multiplier factors are distributed according to the equivalent weight, 20 of each one, and 100 in total.

According to THBV evaluation method of single factor calculation formula of $\mathrm{Mi}=0.78 \alpha \mathrm{i}+$ $0.11 \beta \mathrm{i}+0.11 \chi \mathrm{i}(\mathrm{Mi}$ is comprehensive score for the $\mathrm{i}$ factor, $\alpha \mathrm{i}, \beta \mathrm{i}, \chi \mathrm{i}$ is the value of the $\mathrm{i}$ factors given by the relevant experts, competitive enterprises and by a review of the time-honored brand internal experts assessment). And calculate the cumulative score of the two factors, then mapped to the brand intensity multiplier, which can figure out the brand multiplier.

Table 4 Brand multiplier indicators

\begin{tabular}{cc}
\hline & Brand multiplier mapping \\
\hline Kouzijiao & 1.56 \\
Gujing & 1.67 \\
\hline
\end{tabular}

The brand multipliers of Gujing and Kouzijiao are slightly different, and the brand multiplier of Gujing is higher and close to 0.1 compared to that of Kouzijiao.

\subsubsection{Calculation of brand value (BV)}

According to the above BAV and BM of brand advantage, the brand value of Gujing liquor and Kouzijiao liquor can be obtained by multiplying them according to the formula 4 in the THBV model as followed:

Table 5 Brand value indicators

\begin{tabular}{cccc}
\hline & BAV & BM & BV \\
\hline Kouzijiao & 102.25 & 1.56 & 159.5099 \\
Gujing & 110.57 & 1.67 & 186.8633 \\
\hline
\end{tabular}

The value of Gujing liquor is about $18 \%$ which is higher than that of Kouzijiao liquor, which reflects the huge gap between the values of time-honored brands.

\subsection{Brand value evaluation results analysis of Chinese time-honored brands}

According to BAV, BM and BV indicators calculated in the THBV model, the difference 
between the values of Kouzijiao brand land Gujing can be found.

About BV, BV of Kouzijiao and Gujing are positive, so THBV model is feasible. The brand value of the two brands is good with certain competitiveness, but the numerical value is not high, what means the brand value needs to be improved.

BAV analysis reflects the premium level of brands in the market. The BAV of Gujing is higher than that of Kouzijiao, implying that consumers get a high premium in the former one. PBAV of Gujing is higher than that of Kouzijiao. This is mainly due to the gap between after-tax profits. Although they are both time-honored brands, the profitability of Gujing is higher than the Kouzijiao.

$\mathrm{BM}$ analysis is the social and cultural implication of the brand to the brand premium ability of leverage. Likewise, BM of Gujing is higher than that of Kouzijiao, reflecting its social and cultural implications of the brand to leverage brand premium ability is stronger. Five aspects of integrated performance of Gujing are better than the Kouzijiao, which embodies the Gujing is more survivable than the other one.

In conclusion, as liquor time-honored brands, both Gujing and Kouzijiao have space to improve. Finding out the differences and analyze the reasons of them, we can find out the bottleneck of development of liquor time-honored brand values, and put forward a targeted solution for them.

\section{Methods to Improve Brand Value of "Chinese Time-honored Brand"}

The profitability of the two time-honored brands of liquor needs to be strengthened, which also represents the general commonality of time-honored brands of liquor. As one of the greatest driving forces of profitability, innovation should be highly valued.

Surge in modern society, in the tide of "Internet +" Kouzijiao liquor and Gujing liquor as liquor brands should grasp the opportunity, using the Internet pattern to broaden the publicity channels, and innovative sales model, also further improve the profit ability, then enhance their competitiveness and vitality, giving the power to the secondary development of the time-honored brands in modern society.

Chinese time-honored brand enterprises should be in the enterprise internal organization specialized training and guidance, and make their staff utilize the internet, then gradually begin to run online shops, and cooperate more third-party e-commerce platform in order to better implement "network store" project. It also strengthens the credit rating of flagship stores on relevant business platforms, so that buyers believe the quality of the goods of the seller and are willing to purchase on the Internet.

\section{References}

[1] Aaker. D. A. Managing Brand Equity [M]. New York: the Free Press. 1991.

[2] Qian minghui, Chen Dan, Lang Lingyu, Li Qi. Research on brand evaluation of "Chinese time-honored brand" --Quantitative analysis based on news text [J]. Business research.2017 (1): 11-12.

[3] Tao jun. Brand extension and feedbacks of "Chinese time-honored brand" [J]. Modern management science. 2009(4):73-75.

[4] Wang chengrong, Li cheng, Wang Yujun. Time-honored brand value [M]. Beijing: China economic press, 2012.

[5] Wang chao, Shen Yang. Evaluation and promotion measures of the brand value of Shenyang "time-honored brand"

[J]. Journal of northern university of nationalities (philosophy and social science edition), 2015 (6): 27-31.

[6] Chen Yarong, Guo Jing. Analysis on the evaluation system of brand competitiveness from the perspective of consumers -- an empirical study based on principal component analysis [J]. Consumer guide, 2010 (8)

[7] Wang Bo, Zhang Lin. Research on comprehensive evaluation index system of brand competitiveness based on Dirichlet model [J]. Journal of tianjin university: social science edition, 2012 (5). 